\title{
Mechanistic insights into electrocatalytic reactions provided by SERS
}

Alexander J. Keelera ${ }^{a}$, Giancarlo R. Salazar-Banda ${ }^{\mathrm{b}}$, Andrea E. Russell ${ }^{\star}$

a School of Chemistry, University of Southampton, Highfield, Southampton, SO17 1BJ, UK

${ }^{b}$ Laboratory of Electrochemistry and Nanotechnology, Institute of Technology and

Research, 49032-490, Aracaju, Sergipe, Brazil and Process Engineering Postgraduate Program (PEP), Universidade Tiradentes, 49032-490, Aracaju, Sergipe, Brazil.

\section{Abstract}

In situ vibrational spectroscopy can provide molecular level mechanistic insights missing from purely electrochemical measurements. Surface enhanced Raman spectroscopy (SERS) is a particularly promising method and is employed in aqueous and non-aqueous studies of a variety of electrode reactions. Enhancement of the weak Raman signal is achieved by structuring the electrode surface or by use of SERS probes. This review article highlights the recent use of SERS to study several important electrode reactions; oxygen reduction and evolution, carbon monoxide oxidation and carbon dioxide reduction, and the electrocatalytic oxidation of small organic molecules such as formic acid.

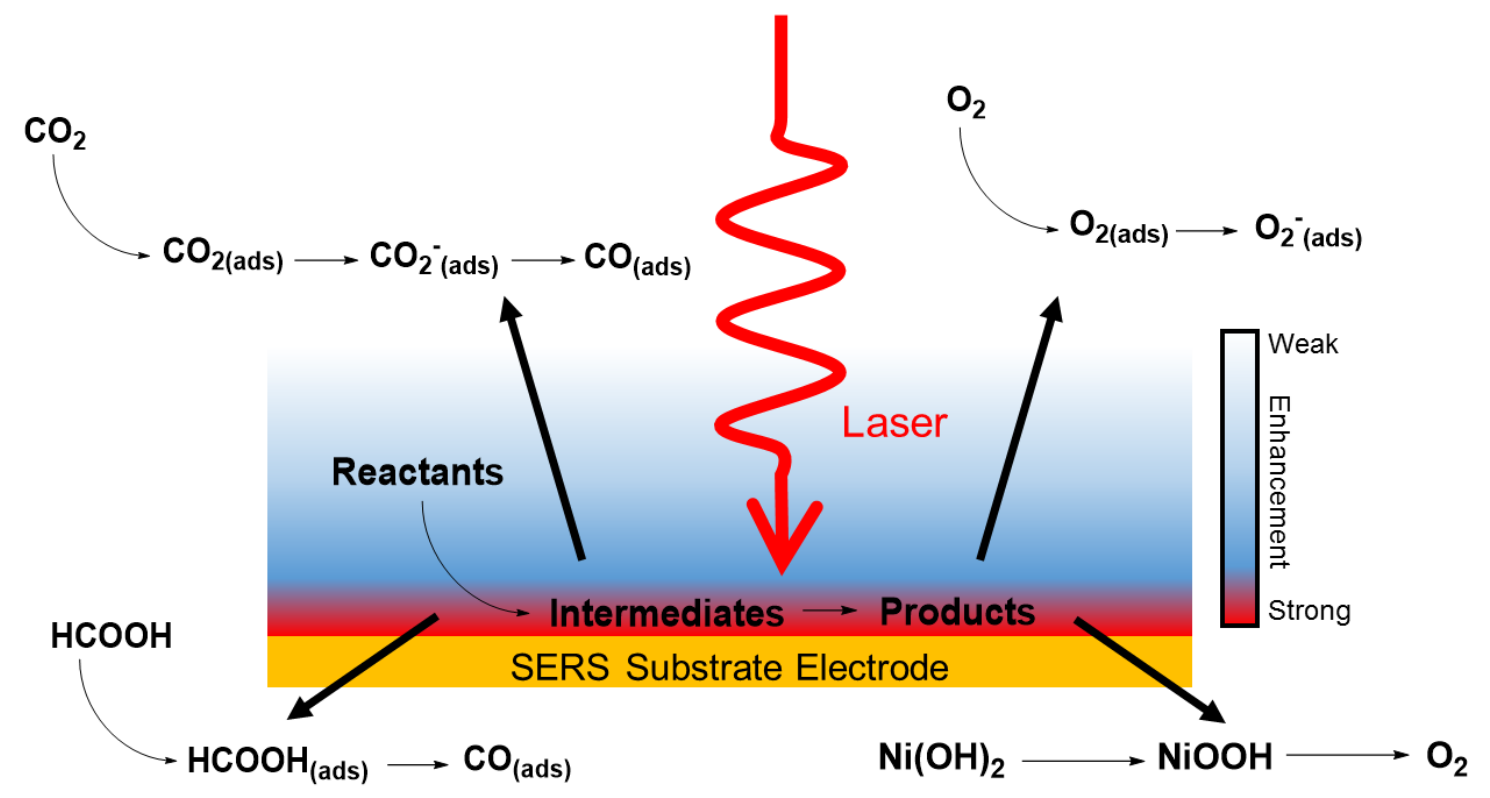

Figure 1: A schematic diagram of the study of electrochemical reaction mechanisms using SERS depicting the reactions covered in this review. The SERS substrate electrode must be structured in a manner to provide the SERS enhancement (see Figure 2) and the reactants, intermediates, and products detected must be located in the region in which the enhancement of the Raman signal is strong for effective detection. 


\section{Introduction}

Surface enhanced Raman spectroscopy (SERS) ${ }^{1}$ was discovered in the 1970s in an experiment that sought to characterise species adsorbed on or near electrode surfaces during electrochemical reactions ${ }^{2}$. The enhancement observed with a roughened $\mathrm{Ag}$ electrode ${ }^{3}$ was orders of magnitude greater than that expected and was later attributed to electromagnetic ${ }^{4}$ and chemical ${ }^{5}$ effects, with the former now understood to provide most of the typically $10^{6}$-fold enhancement. In the many years since the initial discovery there have over 19,000 SERS papers published, most of which describe the development of new or improved SERS substrates ${ }^{6}$, further study of the SERS mechanism ${ }^{7}$, and the development of advanced SERS techniques, such as tip-enhanced Raman spectroscopy (TERS), as evidenced by the two most recent Faraday Discussions on SERS ${ }^{8,9}$ and some of the reviews published in this journal ${ }^{10,11,12}$.

SERS offers several advantages over other vibrational spectroscopic probes of electrode surfaces such as FTIR. The enhancement is strongest for molecules at or on the surface of substrate $\mathrm{e}^{13,14}$ and the metal-adsorbate vibrations are readily observed, whereas these would be in the far-infrared region for IR studies, where the strong absorbance by the solvent obscures the rather weak signals, causing experimental difficulties ${ }^{15}$. Water and many other solvents used in electrochemistry do not have strong Raman signals and thus thin-layer cells with micron-scale pathlengths are not necessary. Additionally, molecules such as $\mathrm{O}_{2}$ can be observed by Raman making SERS particularly useful in the study of the oxygen reduction and evolution reactions, as will be illustrated later in this review.

SERS substrates have advanced considerably from the highly roughened/disordered metal surfaces characteristic of the original discovery, although such highly disordered surfaces are still used, as understanding of the role of plasmonics and the (optical) electric field strength in achieving the enhancement improved. This understanding has enabled the design of nanostructured substrates in which the plasmons are focussed (e.g. sharp tips ${ }^{16}$ or dendrites ${ }^{17}$ ) or confined (e.g. sphere segment voids/SSV ${ }^{18,19,20}$ ) as well as the development of SERS probes (e.g. shell isolated nanoparticles/SHIN ${ }^{21,22,23}$ ) that can be used to study non-SERS active surfaces as depicted in Figure $2 a$. All of which have been employed to study electrode reactions. 


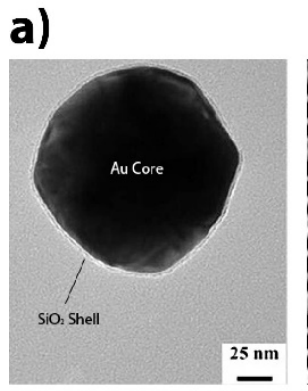

e)

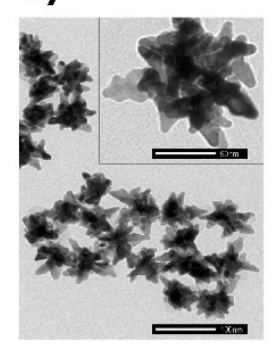

b)

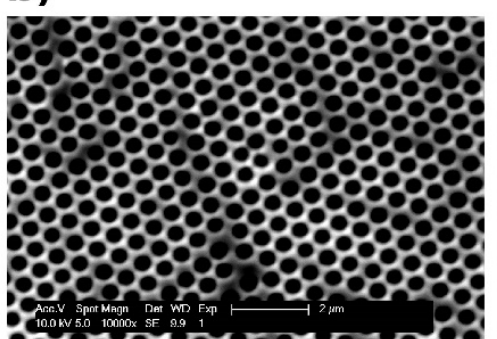

f)

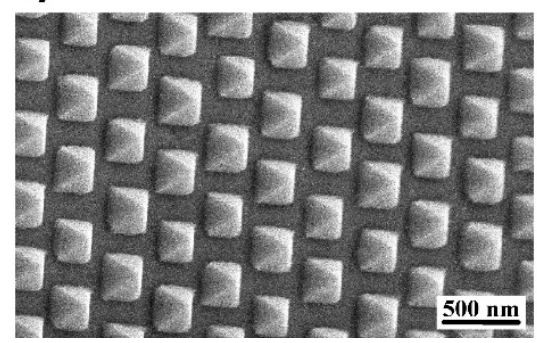

c)

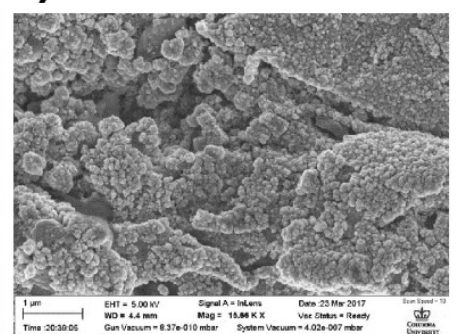

g)

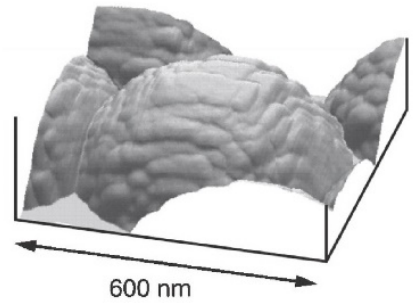

Figure 2: A selection of SERS substrates: a) Au@ $\mathrm{SiO}_{2} \mathrm{SHINERS} \mathrm{particles}^{24}$, b) Au sphere segment voids (original image), c) roughened $\mathrm{Cu}^{30}$, d) $\mathrm{Au}$ nanotriangles $\left.{ }^{16}, \mathrm{e}\right) \mathrm{Au}$ nanostars ${ }^{17}$, f) Au nanopyramids ${ }^{25}$ and g) Ag film-over-nanospheres ${ }^{16}$. Adapted with permission from original content authors.

Alongside these developments in SERS substrates, there has been improved understanding that the structure of electrode surfaces can affect the outcome of electrode reactions through the study of single crystal surfaces and nanoparticles. Thus, it may be inappropriate to assume that the structure of the SERS substrate (roughened or otherwise intentionally nanostructured) can be treated as an insignificant parameter. The use of SHIN particles provides a means of achieving enhancement on non-active surfaces such as smooth single crystal metal surfaces ${ }^{23}$ or highly absorbing (black electrode) surfaces such as glassy carbon (GC) ${ }^{26}$. However, casting SHIN particles on an electrode surface may also cause a perturbation to the reaction by restricting mass transport.

In this brief review we present some of the most recent SERS studies of electrode reactions to highlight the mechanistic understanding that can be achieved and encourage further use of SERS to study electrode reactions. In doing so, note is made of where the authors have ensured that, at least some, of the electrochemical data that is presented is obtained using the same electrodes as those used for the SERS measurements.

\section{Oxygen electrochemistry}

The electrochemical reactions of oxygen are both technologically important (fuel cells, water electrolysers, air-batteries, etc.) and well suited to study by SERS as the species involved are Raman active. In particular, the SERS has proved useful in the study of the oxygen reduction reaction (ORR) in the aprotic solvents used in lithium-air (oxygen) batteries, which 
may be a promising power source for electric vehicles if the barriers such as low cycle life and the formation of undesirable byproducts can be overcome.

Galloway and Hardwick ${ }^{26}$ employed SHIN particles to study the ORR in DMSO at smooth $\mathrm{Au}, \mathrm{Pt}, \mathrm{Pd}$, and $\mathrm{GC}$ and in acetonitrile at GC electrode surfaces, showing that the SHINERS method was useful at each of these electrode surfaces. In DMSO they showed that the interaction of the superoxide $\mathrm{O}_{2}{ }^{-}$intermediate with the electrode surface was dependent on the nature of that surface as suggested by the cyclic voltammetric results obtained for electrodes in DMSO that were free of the SHIN particles, the lack of any effects of SHIN particles on the voltammograms for the GC surface are shown in the supporting information of their paper. The SHINERS results suggest that $\mathrm{O}_{2}^{-}$lies flat on $\mathrm{Pt}$ at more positive potentials, switching to an end-on orientation as the potential is made more negative, whilst the end-on orientation is preferred at all potentials for $\mathrm{Au}$ and $\mathrm{Pd}$, as evidenced by metal oxide peaks observed between 400 and $550 \mathrm{~cm}^{-1}$ (Figure 3a). In contrast, no peaks were observed for the metal metal oxide interaction at GC and only peaks attributed to $\mathrm{O}_{2}^{-}$in solution and weakly interacting with the GC surface were observed. Other peaks were observed at GC attributed to $\mathrm{HO}_{2}$ and $\mathrm{LiO}_{2}$, the latter observed in the presence of $0.5 \mathrm{~mol} \mathrm{dm}^{-3} \mathrm{LiClO}_{4}$ (Figure 3b). $\mathrm{LiO}_{2}$ can decompose to produce $\mathrm{Li}_{2} \mathrm{O}_{2}$, which is insulating and is, thus, an undesirable byproduct. Qiao and $\mathrm{Ye}^{27}$ used SERS at sputtered Au electrodes, employed for both the electrochemical and Raman measurements, to investigate the use of tetrathiafulvalene (TTF) as a redox mediator, designed to facilitate the oxidation of $\mathrm{Li}_{2} \mathrm{O}_{2}$ during the oxygen evolution reaction (OER) in DMSO and thus improve the cycle life of the $\mathrm{Li}_{-} \mathrm{O}_{2}$ battery. Their results showed that at the Au electrode the $\mathrm{TTF}^{+}$ions produced were mainly consumed by the oxidative decomposition of $\mathrm{LiO}_{2}$ during ORR/OER cycles in contrast to the desired action (Figure 3c). In contrast, at porous carbon electrodes, for which they were unable to obtain SERS, the ex situ Raman data supported TTF mediated oxidation of $\mathrm{Li}_{2} \mathrm{O}_{2}$, but also showed that the excess $\mathrm{TTF}^{+}$formed during round trip

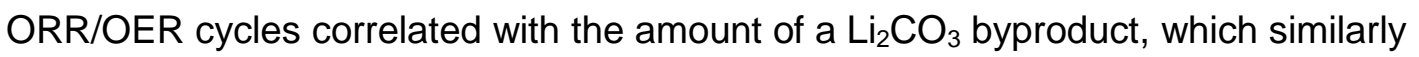
suggested that TTF would not be a good redox mediator at this surface. The insights provided by SERS in both of these studies are highly valuable, enabling identification of byproducts and furthering understanding of the dependence of their interaction with the electrode surface on the nature of that surface. 


\section{a)}

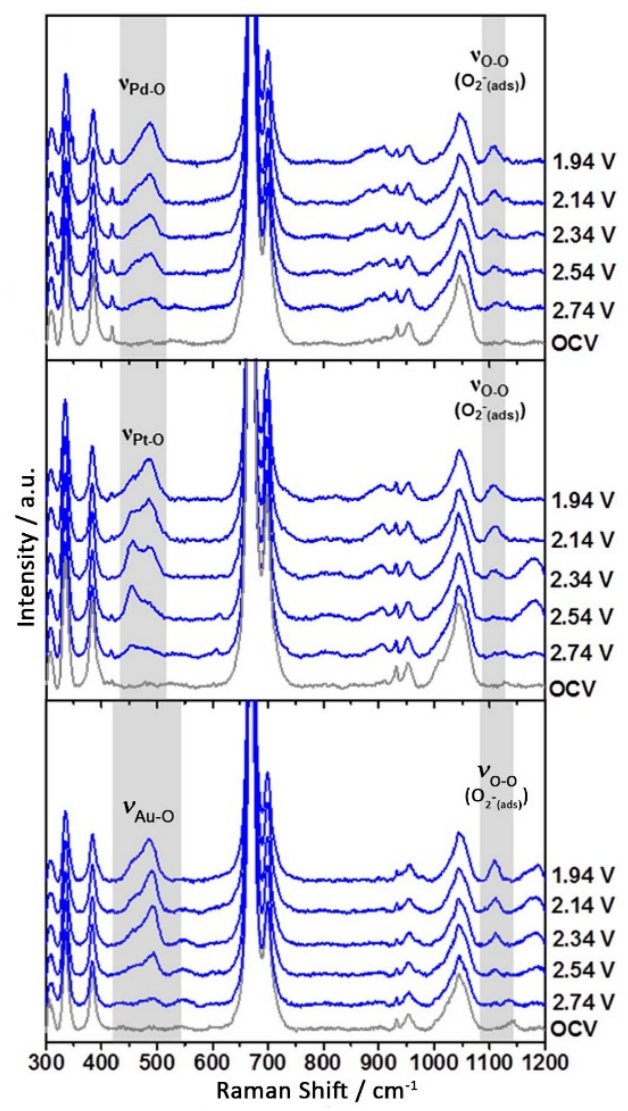

b)

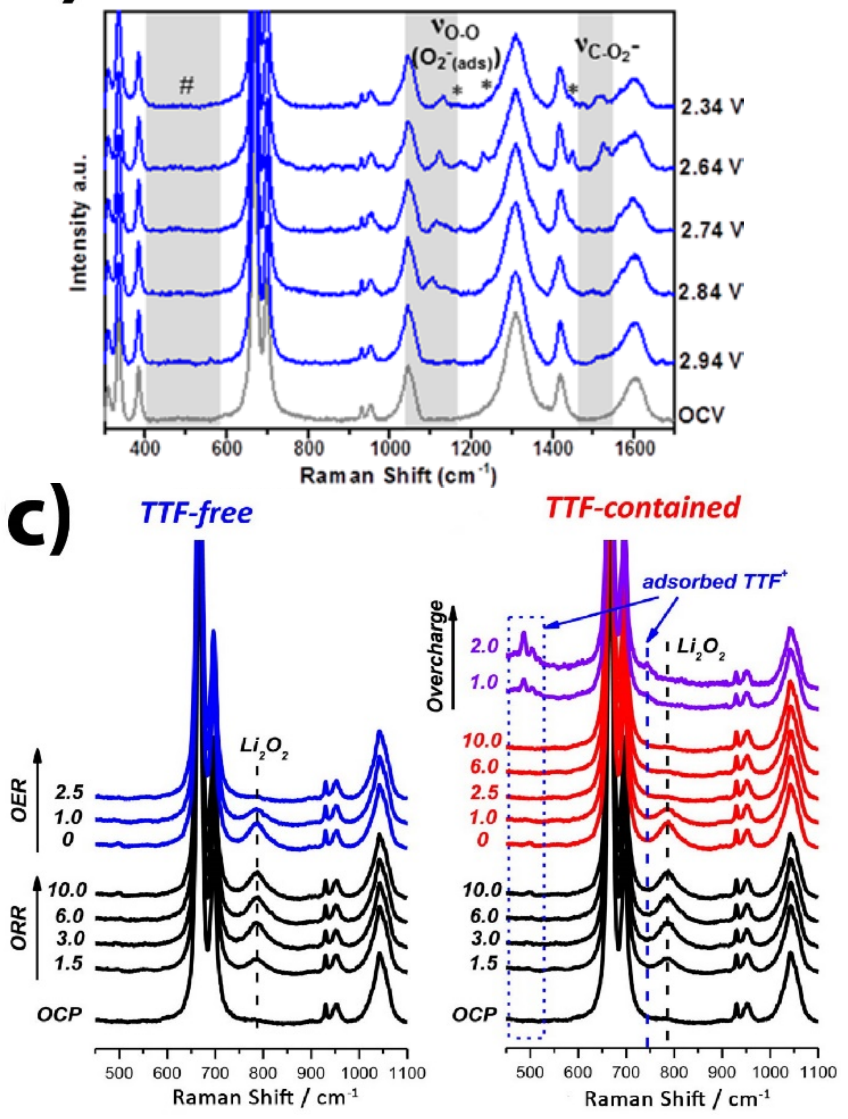

Figure 3: In situ SERS spectra of a) the ORR with SHIN's on the surface of polycrystalline metals $\mathrm{M}, \mathrm{Pd}$ (top), $\mathrm{Pt}$ (middle) and $\mathrm{Au}$ (bottom) in $\mathrm{O}_{2}$ saturated $0.1 \mathrm{M}$ TBAClO${ }_{4} / \mathrm{DMSO}$ electrolyte. Potentials vs. $\mathrm{Li} / \mathrm{Li}^{+}{ }^{26}$ The peaks highlighted show the formation of the metal oxides (M-O vibrations around $450-500 \mathrm{~cm}^{-1}$ ) and the $\mathrm{O}-\mathrm{O}$ vibration of $\mathrm{O}_{2}^{-}$around $1110 \mathrm{~cm}^{-1}$. Increased intensity of both indicates both an increase in the coverage or concentration and a more upright or end-on adsorption site of $\mathrm{O}_{2}{ }^{-}$. The other peaks, present at the open circuit voltage (OCV), are all attributed to the DMSO solvent. b) the ORR with SHIN's on a GC electrode also in $\mathrm{O}_{2}$ saturated $0.1 \mathrm{M} \mathrm{TBAClO}_{4} / \mathrm{DMSO}$. Potentials vs. $\mathrm{Li}^{2} \mathrm{Li}^{+}{ }^{26}$ In contrast to the spectra shown in a), no $\mathrm{M}-\mathrm{O}$ vibration of adsorbed $\mathrm{O}_{2}^{-}$is observed \#, confirming correct operation of the SHIN particles, peaks are observed $\mathrm{O}_{2}{ }^{-}$at $1110 \mathrm{~cm}^{-1}$ and at less positive potentials for $\mathrm{C}-\mathrm{O}_{2}^{-}$showing that weakly interacting $\mathrm{O}_{2}^{-}$moves to a less favourable adsorption site as the concentration/coverage increases. The bands marked * are attributed to $\mathrm{HO}_{2}$ at $1179 \mathrm{~cm}^{-1}$ and the interaction of $\mathrm{HO}_{2}{ }^{-}$with $\mathrm{GC}$ at $1450 \mathrm{~cm}^{-1}$ due to trace water content. c) the ORR and OER on sputtered Au electrodes in $\mathrm{O}_{2}$ saturated $0.5 \mathrm{M}$ $\mathrm{LiClO}_{4}$ in DMSO showing the formation of $\mathrm{Li}_{2} \mathrm{O}_{2}$ during the ORR and its consumption during OER . ${ }^{27}$ Adapted and reproduced with permission of Galloway and Hardwick and Qiao and Ye. 
The borrowed SERS strategy, in which a SERS active substrate is coated with a thin layer of another material, thereby transferring the enhancement to the new surface, was utilised by Diaz-Morales et al. ${ }^{28}$ to study OER on nickel oxyhydroxide (NiOOH) surfaces. Approximately 5 monolayers of $\mathrm{Ni}$ were plated on to an electrochemically roughened $\mathrm{Au}$ SERS substrate. The $\mathrm{pH}$ dependent $\mathrm{Ni}(\mathrm{OH})_{2} / \mathrm{NiOOH}$ redox couple is clearly visible in the cyclic voltammograms of this surface obtained in alkaline to neutral $\mathrm{pH} \mathrm{NaOH} / \mathrm{NaClO}_{4}$ electrolytes. The SERS show peaks associated with the Ni hydroxide and oxyhydroxide species as well as an active oxygen species with a peak between $800-1150 \mathrm{~cm}^{-1}$, which was identified as the superoxo O-O vibration of $\mathrm{NiOO}^{-}$. They go on to suggest that this species acts as the $\mathrm{O}_{2}$ precursor when the $\mathrm{pH}>11$.

\section{Electrochemistry of carbon monoxide and carbon dioxide}

The concept of using the electrochemical reduction of $\mathrm{CO}_{2}$ to produce a variety of fuels and commodity chemicals is an increasing research area in electrocatalysis. ${ }^{29} \mathrm{CO}$ is both a product (partial reduction) and proposed intermediate in this process as and in the electrocatalytic oxidation of organic compounds, such as methanol, as well as being a contaminant in reformate produced $\mathrm{H}_{2}$ used as a fuel in low temperature fuel cells. SERS measurements are able to probe the metal-adsorbate vibrations providing information that is complementary to that obtained using IR and, where the catalyst is a roughened electrode surface or nanoparticles, directly study the working catalyst. Two studies of $\mathrm{CO}_{2}$ reduction and one of $\mathrm{CO}$ oxidation are highlighted below.

High surface area Cu electrodes are one of the more promising electrocatalysts for $\mathrm{CO}_{2}$ reduction. Chernyshova and coworkers ${ }^{30}$ studied the reaction at roughened $\mathrm{Cu}$ electrodes, obtaining the electrochemical and SERS data using the same surfaces and combining these with density functional theory (DFT) and isotope exchange experiments to provide further information regarding the reaction mechanism. In particular they were able to show that the first intermediate of the $\mathrm{CO}_{2}$ conversion to formate on $\mathrm{Cu}$ is a carboxylate anion ${ }^{*} \mathrm{CO}_{2}{ }^{-}$coordinated to the surface through one of its $\mathrm{C}-\mathrm{O}$ bonds with the $\eta^{2}(\mathrm{C}, \mathrm{O})-\mathrm{CO}_{2}{ }^{-}$ structure (Figure 4). Consequently, the authors validated Hori's hypothesis ${ }^{31,32}$ that $\mathrm{CO}_{2}$ electroreduction starts with a common first intermediate. The $\eta^{2}(\mathrm{C}, \mathrm{O})-\mathrm{CO}_{2}{ }^{-}$structure was also observed at potentials much more anodic than the onset of the $\mathrm{CO}_{2}$ electroreduction. This suggests a critical role of additional cooperative effects such as surface defects, residual surface oxide, and co-adsorbed electron donors, which are yet to be understood. Finally, it was concluded that the electrocatalytic activity of the metal is related to the strengths of the metal- $\mathrm{C}$ and metal-O bonds of $\eta^{2}(\mathrm{C}, \mathrm{O})-\mathrm{CO}_{2}{ }^{-}$. 

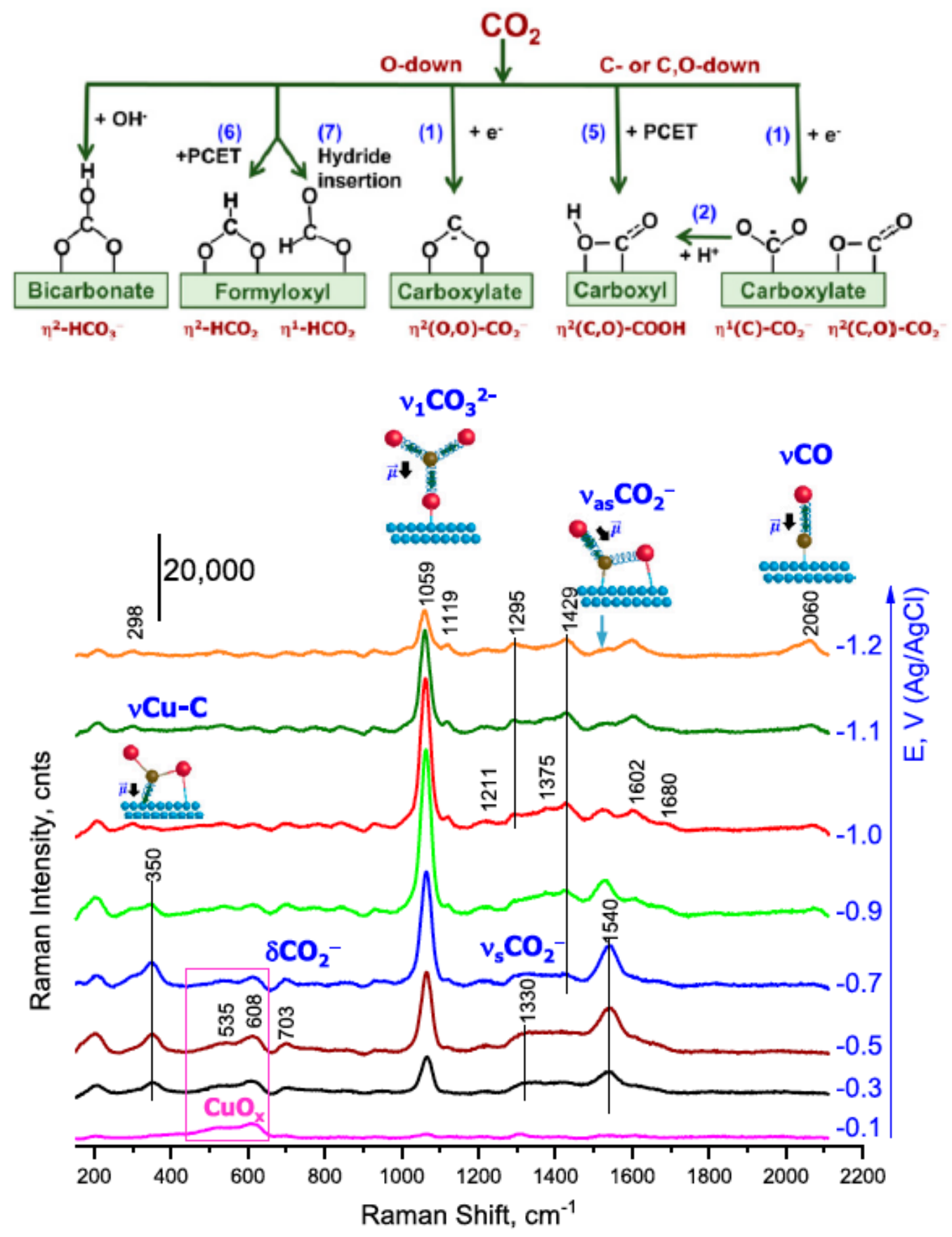

Figure 4: Proposed first intermediates of $\mathrm{CO}_{2}$ reduction and potential dependant SERS spectra of roughened $\mathrm{Cu}$ in $\mathrm{CO}_{2}$ saturated $0.1 \mathrm{M} \mathrm{NaHCO}_{3}$. Reproduced with permission from Chernyshova et al. ${ }^{30}$ Attribution of peaks in the spectra to the various intermediates in $\mathrm{CO}_{2}$ reduction are shown. The intensities of the peaks increase with coverage of the adsorbed species, but are also dependent on the orientation, with those vibrational modes that have a dipole component $\vec{\mu}$ perpendicular to the Cu surface exhibiting the largest peaks. Thus the relative intensities of the peaks are not straightforwardly related to the relative coverages of the species. 
Whilst $\mathrm{CO}_{2}$ reduction at $\mathrm{Cu}$ produces the most hydrocarbons, reduction at $\mathrm{Ag}$ and $\mathrm{Au}$ electrodes yields the greatest Faradaic efficiency for $\mathrm{CO}$ production ${ }^{33}$, which is attributed to the weaker binding of $\mathrm{CO}$ to these surfaces. Modification of Ag electrode surfaces by $\mathrm{N}$ containing additives had been shown to enhance $\mathrm{CO}_{2}$ conversion ${ }^{34}$ and Oberst et al. ${ }^{35}$ extended this work to Au surfaces, studying the adsorption of the modifiers (benzotriazole and ethanolamine) and $\mathrm{CO}$ adsorption using SERS at roughened Au electrodes in alkaline electrolyte. They compared their results to cyclic voltammograms and extracted Tafel slopes obtained at smooth Au electrodes. In contrast to their earlier findings on Ag, addition of benzotriazole was found to have little effect on both the $\mathrm{CO}_{2}$ activity and product distribution, which they attribute to the fact that $\mathrm{CO}$ adsorption on $\mathrm{Au}$ is much weaker than that on $\mathrm{Ag}$ (ca. $0.28 \mathrm{eV}$ versus ca. $0.40 \mathrm{eV}$, respectively). ${ }^{36}$ Modification of the surface by ethanolamine, which is a $\mathrm{CO}_{2}$ scavenger did enhance the activity on $\mathrm{Au}$, which they attributed to a local increase in the local $\mathrm{CO}_{2}$ availability at the Au electrode surface.

Fuel cell electrocatalysts are typically nanoparticle in nature, which poses difficulties for SERS characterisation, especially for non-SERS active Pt-based alloy nanoparticles, which are the more common electrocatalysts for the $\mathrm{H}_{2}$ anode reaction in reformate fuelled cells. Liang and coworkers ${ }^{37}$ have taken an innovated approach to the study of such alloy nanoparticles by anchoring the Pt-based nanocrystals onto the $\mathrm{SiO}_{2}$ shell of $\mathrm{SHIN}$ particles. The modified SHIN particles were then used to study catalytic $\mathrm{CO}$ electrooxidation on Pt and PtFe bimetallic nanoparticles. The modified SHIN particles were deposited on to a GC electrode for both the voltammetric and SERS measurements and the $\mathrm{Pt}_{1} \mathrm{Fe}_{\mathrm{x}}(\mathrm{x}=0,0.5,1$, 1.5) particles were activated by cycling from $-0.25 \mathrm{~V}$ to $1.0 \mathrm{~V}$ vs. SCE in $0.1 \mathrm{~mol} \mathrm{dm}^{-3} \mathrm{HClO}_{4}$, which resulted in dissolution of some of the Fe to produce a Pt rich surface. Spectra were collected in $\mathrm{CO}$ saturated solution, with peaks corresponding to the $\mathrm{Pt}-\mathrm{CO}$ and $\mathrm{C}-\mathrm{O}$ stretching modes being observed, with greater intensities observed for those catalysts which contained Fe. The frequency of the Pt-CO stretching peak was found to decrease with increasing Fe content, indicating a change to the electronic state of the Pt ( $d$-band centre), which weakens the Pt-CO bond and enhances the electrocatalytic activity beyond that accounted for by the increased surface area of the particles upon leaching of Fe from the surface.

\section{Formic acid oxidation}

The electrooxidation of formic acid continues is of interest both as an intermediate in the oxidation of other small organic molecules and as fuel itself for direct formic acid fuel cells ${ }^{38}$. Pt monolayers coated Au nanoparticles (Au@Pt) have been shown to be active electrocatalysts for formic acid oxidation at room temperature ${ }^{39}$. Two recent mechanistic SERS studies have been reported. The first by Jeong and Kim ${ }^{40}$ used Au@Pt substrates 
that were prepared by self-terminating electrodeposition of Pt onto dendritic Au rod (DAR) structures and both the electrochemical and SERS data were obtained using the same electrodes. The electrocatalytic activity of formic acid was found to be dependent on the $\mathrm{Pt}$ coverage and thickness. CO was used as a probe to determine the number of potential step cycles required to fully cover the Au surface with Pt through observation of the characteristic Pt-CO modes between 380-490 $\mathrm{cm}^{-1}$ and the C-O stretching mode on Au at $2094 \mathrm{~cm}^{-1}$. Surfaces with island-type Pt layers on Au (low Pt coverage) exhibited electrochemical behaviour attributed to the direct oxidation of formic acid, whilst the indirect pathway, wherein $\mathrm{CO}_{\text {ads }}$ is as an intermediate, was observed as the Pt coverage increased. In contrast, $\mathrm{CO}_{\text {ads }}$ was observed in the SERS of the low Pt coverage surfaces, indicating that the indirect electrooxidation of formic acid occurs.

In a more recent paper, Xie et al. ${ }^{41}$ combined EC-SERS and high-frequency heating technology using a thermocouple microelectrode loading with round Au@Pt nanoparticles which also served as the SERS substrate to investigate the formic acid electrooxidation at different temperatures. The cyclic voltammetry data (from $25^{\circ} \mathrm{C}$ to $100{ }^{\circ} \mathrm{C}$ ) indicated that formic acid oxidation was enhanced significantly as the temperature increased. The SERS data showed that $\mathrm{CO}$ oxidative desorption from the Pt shell was promoted at higher temperatures, accounting for the improved the catalytic activity, but did not support any change in the mechanism of the formic acid oxidation reaction.

\section{Summary}

45 years after its discovery SERS remains a valuable tool for the study of electrode processes and the SERS studies presented herein highlight the mechanistic insights that can be achieved, particularly for electrocatalytic reactions in which the reactants or intermediates are bound to the electrode surface. However, given the need to nanostructure the surface or use invasive probes to achieve enhancement, it is view of the authors that continued care needs to be taken when comparing electrochemical data obtained on other electrode surfaces to the SERS data. This is not meant as a direct criticism of those papers reviewed, but more as a request to those who continue to employ SERS to study electrode reactions, especially those that may prove to be structure sensitive or for which perturbation of mass transport may be important. As illustrated by several of the studies presented above, the nanostructures required for SERS or to achieve the electrocatalytic activity can in fact prove to be the same, making SERS an excellent method for the mechanistic study of electrocatalytic reactions. 


\section{Acknowledgements}

The authors acknowledge funding from the University of Southampton, the EPSRC Doctoral Training Account (AJK), and the Universidade Tiradentes and the Coordination for the Improvement of Higher Education Personnel from Brazil - CAPES (grant: 88881.121097/2016-01) for sabbatical leave funding (GRSB).

\section{Author contributions}

AJK, GRSB, and AER contributed equally to the preparation of this manuscript.

\section{Conflict of interest}

The authors declare no competing financial interests.

\section{References and recommended reading}

Papers of particular interest, published within the period of review, have been highlighted as

* Paper of special interest

** Paper of outstanding interest.

${ }^{1}$ Van Duyne RP: Laser excitation of Raman scattering from adsorbed molecules on electrode surfaces. Chem. Biochem. Appl. Lasers 1979, 4:101-185.

The paper in which the term SERS was coined.

${ }^{2}$ Fleischmann M, Hendra PJ, McQuillan AJ: Raman spectra of pyridine adsorbed at a silver electrode. Chem. Phys. Lett. 1974, 26:163-166. doi:10.1016/0009-2614(74)85388-1. The original SERS study using a roughened Ag electrode. The authors knew that they had observed signals much more intense than expected, but did not explicitly mention this.

${ }^{3}$ McQuillan AJ: The discovery of surface-enhanced Raman scattering. Notes. Rec. $R$. Soc. 2009, 63:105-109. doi:10.1098/rsnr.2008.0032

This article is a recollection by Jim McQuillan of the discovery of SERS and explains why they didn't mention the magnitude of the enhancement in the original paper.

4 Jeanmaire DL, Van Duyne RP: Surface Raman electrochemistry. Part 1. Heterocyclic, aromatic and aliphatic amines adsorbed on the anodised silver electrode. $\mathrm{J}$. Electroanal. Chem. 1977, 84:1-20. doi:10.1016/S0022-0728(77)80224-6

${ }^{5}$ Albrecht MG, Creighton JA, Anomalously intense Raman spectra of pyridine at a silver electrode, J. Am. Chem. Soc. 1977, 99:5215-5219. doi:10.1021/ja00457a071 
${ }^{6}$ Sharma B, Frontiera RR, Henry Al, Ringe E,Van Duyne RP, SERS: Materials, applications, and the future. Mater. Today. 2012 15:16-25. doi:10.1016/S13697021(12)70017-2.

A very useful review of SERS substrates and their current and future applications.

${ }^{7}$ Stiles PL, Dieringer JA, Shah NC, Van Duyne RP, Surface-Enhanced Raman Spectroscopy. Annu. Rev. Anal. Chem. 2008 1:601-626.

doi:10.1146/annurev.anchem.1.031207.112814.

${ }^{8}$ Surface enhanced Raman spectroscopy, Faraday Discussions 132, 2006.

${ }^{9}$ Surface enhanced Raman scattering - SERS, Faraday Discussions 205, 2018.

${ }^{10}$ Yang J., Dong JC, Kumar W, Li JF, Tian ZQ: Probing electrochemical interfaces using shell-isolated nanoparticles-enhanced Raman spectroscopy. Curr. Opin. Electrochem. 2017 1:16-21. doi:10.1016/j.coelec.2016.12.009

11 Touzalin T, Joiret S, Maisonhaute E, Lucas IT: Capturing electrochemical transformations by tip-enhanced Raman spectroscopy, Curr. Opin. Electrochem. 2017 6:46-52. doi:10.1016/j.coelec.2017.10.016

12 Pfisterer JHK, Domke DF, Unfolding the versatile potential of EC-TERS for electrocatalysis, Curr. Opin. Electrochem., 2018 8:96-102. doi:10.1016/j.coelec.2018.03.023

${ }^{13}$ Shanthil M, Thomas R, Swathi RS, George TK, Ag@SiO2core-shell nanostructures: Distance-dependent plasmon coupling and SERS investigation. J. Phys. Chem. Lett. 2012 3:1459-1464. doi:10.1021/jz3004014

${ }^{14}$ Masango SS, Hackler RA, Large N, Henry AI, McAnally MO, Schatz GC, et al., HighResolution Distance Dependence Study of Surface-Enhanced Raman Scattering Enabled by Atomic Layer Deposition. Nano Lett. 2016 16:4251-4259. doi:10.1021/acs.nanolett.6b01276.

${ }^{15}$ Russell $A E$, Rubasingham L, Ballinger TH, Hagans PL: Thin layer effects in in situ farinfrared spectroelectrochemistry, J. Electroanal. Chem., 1997, 422:197-200. doi:0.1016/S0022-0728(96)04891-7

${ }^{16}$ K.A. Willets, R.P. Van Duyne, Localized Surface Plasmon Resonance Spectroscopy and Sensing. Annu. Rev. Phys. Chem. 2007 58:267-297.

doi:10.1146/annurev.physchem.58.032806.104607.

A thorough review of surface plasmon resonance, the effect responsible for the majority of the SERS enhancement. 
${ }^{17}$ Khoury CG, Vo-Dinh T, Gold nanostars for surface-enhanced Raman scattering: synthesis, characterization and optimization. J. Phys. Chem. C. 2008 112:18849-18859. doi:10.1021/jp8054747.

${ }^{18}$ Abdelsalam ME, Bartlett PN, Baumberg JJ, Cintra S, Kelf TA, Russell AE, Electrochemical SERS at a structured gold surface. Electrochem. Commun. 2005 7:740744. doi:10.1016/j.elecom.2005.04.028.

The authors present the suitability of SSV substrates for SERS based electrochemical studies at metal surfaces.

${ }^{19}$ Mahajan S, Cole RM, Soares BF, Pelfrey SH, Russell AE, Baumberg JJ, et al., Relating SERS intensity to specific plasmon modes on sphere segment void surfaces. J. Phys. Chem. C. 2009 113:9284-9289. doi:10.1021/jp900661u.

${ }^{20}$ Kelf TA, Sugawara Y, Cole RM, Baumberg JJ, Abdelsalam ME, Cintra S, et al., Localized and delocalized plasmons in metallic nanovoids. Phys. Rev. B - Condens. Matter Mater. Phys. 2006 74:245415. doi:10.1103/PhysRevB.74.245415.

${ }^{21}$ Li JF, Huang YF, Ding Y, Yang ZL, Li SB, Zhou XS, et al., Shell-isolated nanoparticleenhanced Raman spectroscopy. Nature. 2010 464. doi:10.1038/nature08907.

An excellent introduction into SHINERS and its uses on non-SERS active surfaces. *22 Wang J, Dong JC, Yang J, Wang Y, Zhang CJ, Xu MM, et al., In situ SERS and SHINERS study of electrochemical hydrogenation of $p$-ethynylaniline in nonaqueous solvents. Electrochem. Commun. 2017 78:16-20. doi:10.1016/j.elecom.2017.03.015.

An investigation into the effect of surface plasmon resonance on the catalysis of $p$ ethynylaniline hydrogenation at roughened and single crystal surfaces. In addition, showing that when using SHINs the $\mathrm{SiO}_{2}$ layer blocks this phenomenon.

*23 Cabello G, Chen XJ, Panneerselvam R, Tian ZQ, Potential dependent thiocyanate adsorption on gold electrodes: a comparison study between SERS and SHINERS. J. Raman Spectrosc. 2016 47:1207-1212. doi:10.1002/jrs.4944.

The authors present new insights into $\mathrm{N}$ or $\mathrm{S}$ dominated thiocyanate binding on Au vS. potential, including the reassignment of the traditionally mischaracterized Au-S vibrational mode.

${ }^{24}$ Tian XD, Liu BJ, Li JF, Yang ZL, Ren B, Tian ZQ, SHINERS and plasmonic properties of Au Core SiO2 shell nanoparticles with optimal core size and shell thickness. J. Raman Spectrosc. 2013 44:994-998. doi:10.1002/jrs.4317. 
${ }^{25}$ Lin TH, Linn NC, Tarajano L, Jiang B, Jiang P, Electrochemical SERS at periodic metallic nanopyramid arrays. J. Phys. Chem. C. 1132009 113:1367-1372.

doi:10.1021/jp809363m.

**26 Galloway TA, Harwick LJ: Utilising in situ electrochemical SHINERS for oxygen reduction studies in aprotic solvents. J. Phys. Chem. Lett. 2016 7:2119-2124. doi: 10.1021/acs.jpclett.6b00730

This article demonstrates the use of SHINERS to obtain information about both the electrode surface and species in the solution away from the electrode surface, thus providing a greater depth of understanding of the ORR.

*27 Qiao Y, Ye S: Spectroscopic investigation for oxygen reduction and evolution reactions with tetrathiafulvalene as a redox mediator in $\mathrm{Li}-\mathrm{O}_{2}$ battery. J. Phys. Chem. C., 2016 123:15830-15845. doi:10.1021/acs.jpcc.5b11692

This article is highlighted for the clarity of the presentation of the electrochemical data that accompany the SERS, thus providing much deeper mechanistic insights and facilitating later comparison to other experiments.

${ }^{28}$ Diaz-Morales O, Ferrus-Susedra D, Koper MTM: The importance of nickel oxyhydroxide deprotonation on its activity towards electrochemical water oxidation. Chem. Sci. 2016 7:2639-3645. doi:10.1039/C5SC04486C

${ }^{29}$ Appel AM, Bercaw JE, Bocarsly AB, Dobbek H, DuBois DL, Dupuis M, Ferry JG, Fujita E, Hille R, P. Kenis PJA, Kerfeld CA, Morris RH, Peden CHF, Portis AR, Ragsdale SW, Rauchfuss TB, Reek JNH, Seefeldt LC, Thauer RK, Waldrop GL, Frontiers, Opportunities, and Challenges in Biochemical and Chemical Catalysis of CO2 Fixation. Chem. Rev. 2013 113:6621-6658. doi: 10.1021/cr300463y

**30 Chernyshova IV, Somasundaran P, Ponnurangam S: On the origin of the elusive first intermediate of $\mathrm{CO}_{2}$ electroreduction. PNAS 2018 115:E9261-E9270. doi:10.1073/pnas.18022256115

This article demonstrates how the combination of DFT and SERS provides greater mechanistic understanding.

${ }^{31}$ Hori Y: Electrochemical $\mathrm{CO}_{2}$ reduction on metal electrodes. Modern aspects of electrochemistry, eds. Vaynes CG, White RE, Gamboa-Aldeco ME, (Springer, New York), 2008, 2:89-189. 
${ }^{32}$ Hori $\mathrm{Y}$, Wakebe $\mathrm{H}$, Tsukamoto T, Koga O: Electrocatalytic process of CO selectivity in electrochemical reduction of $\mathrm{CO}_{2}$, at metal electrodes in aqueous media. Electrochim. Acta., 1994 39:1833-1839. doi: 10.1016/0013-4686(94)85172-7

${ }^{33}$ Hansen HA, Varley JB, Peterson AA, Norskov JK: Understanding Trends in the Electrocatalytic Activity of Metals and Enzymes for CO2 Reduction to CO. J. Phys. Chem. Lett. 2013 4:388-392. doi: 10.1021/jz3021155

${ }^{34}$ Tomrow CE, Thorson MR, Ma S, Gewirth AA, Kenis PJA: Nitrogen-Based Catalysts for the Electrochemical Reduction of CO2 to CO. 2012 134:19520-19523. doi: 10.1021/ja308217w

${ }^{35}$ Oberst JL, Jhong H-RM, Kenis PJA, Gewirth AA: Insight into the electrochemical reduction of $\mathrm{CO}_{2}$ on gold via surface-enhanced Raman spectroscopy and Ncontaining additives. J. Solid State Electrochem. 2016 20:149-1154. doi:10.1007/s10008015-2874-z

${ }^{36}$ Santiago-Rodriguez Y, Herron JA, Curet-Arana MC, Mavrikakis M: Atomic and molecular adsorption on Au(111). Surf. Sci. 2014 627:57-69. doi:

10.1016/j.susc.2014.04.012

${ }^{37}$ Liang MM, Wang YH, Shao R, Yang WM, Zhang H, Zhang H, Yang ZL, Li JF, Tian ZQ: In situ electrochemical surface-enhanced Raman spectroscopy study of CO electrooxidation on PtFe nanocatalysts. Electrochem. Commun. 2017 81:38-42. doi:1 0.1016/j.elecom.2017.05.022

This article presents a novel approach to the study of nanoparticle electrocatalysts by deposition on to the surface of SHIN particles, followed by deposition on to a glassy carbon electrode, which acts as the current collector.

${ }^{38}$ Jiang K, Zhang HX, Zou S, Cai WB: Electrocatalysis of formic acid on palladium and platinum surfaces: from fundamental mechanisms to fuel cell applications. Phys. Chem. Chem. Phys. 2014 16:20360-20376. doi: 10.1039/C4CP03151B

39 Obradović MD, Tripković AV, Gojković SL: The origin of high activity of Pt-Au surfaces in the formic acid oxidation. Electrochim. Acta. 2009 55:204-209.

doi:10.1016/j.electacta.2009.08.038

40 Jeong $\mathrm{H}$, Kim J: Insights into the electrooxidation mechanism of formic acid on Pt layers on Au examined by electrochemical SERS. J. Phys. Chem. C. 2016 120:2427124278. doi:10.1021/acs.jpcc.6b08611 
In this article SERS is used both to determine how well the Pt layer is covering the underlying Au structure as well as a means to investigate the mechanism of formic acid oxidation.

${ }^{41}$ Xie WC, Ling Y, Zhang YZ, Pan H, Liu GK, Tang J: In-situ electrochemical surfaceenhanced Raman spectroscopy study of formic acid electrooxidation at variable temperatures by high-frequency heating technology. Electrochim. Acta 2018 281:323328. doi: 10.1016/j.electacta.2018.05.167

This article presents a new experimental approach to studying the temperature dependence of electrocatalytic reaction mechanisms. 